\title{
Assessing the progression of metal concentrations in plastic components and printed wiring boards of end-of-life mobile cell phones
}

\author{
Gilbert Umaye ADIE*, Aminat ADETAYO-BALOGUN, and Chidiebere Mmaduka AGUDOSI \\ Department of Chemistry, Faculty of Science, University of Ibadan, Ibadan, Nigeria
}

\begin{abstract}
This study assessed the progression of $\mathrm{Pb}, \mathrm{Cd}$ and $\mathrm{Cr}$ concentrations in plastic components (PCs) and printed wiring boards (PWBs) of 59 end-of-life (EoL) mobile phones (MPs) produced between 2000 and 2015 by two leading original equipment manufacturers (OEMs) patronized by Nigerians. This was done to study the behavior of OEMs in complying with some widely acceptable regulations. Metals in PCs and PWBs of MPs were extracted following EPA 3050B method and extracts were analyzed using atomic absorption spectrophotometry technique. Furthermore, Toxicity Characteristic Leaching Procedure (TCLP) test was conducted on selected samples to assess metal leachability in landfill conditions. Summary of results (mg/kg) for PCs and PWBs for MPs produced by OEM 1 and OEM 2 in brackets ranged thus: PCs, Pb: 5.00 -195 (LOD-1750), Cr: LOD-6050 (LOD-2170) and Cd: LOD-1.00 (LOD-5.75) while PWBs, Pb:1299750 (5.00-12125), Cr: LOD-5488 (LOD- 4000) and Cd: LOD-1.00 (0.25-1.00). There were no regular trends for all metals for both OEMs. Results suggest that a greater percentage of MPs produced till 2015 contained $\mathrm{Pb}$ and $\mathrm{Cr}$ higher than RoHS and TTLC limits. Furthermore, 50\% of TCLP extracts contain Pb higher than EPA limit of $5 \mathrm{mg} / \mathrm{L}$. Therefore, EoL MPs arising in Nigeria should be handled as hazardous materials.
\end{abstract}

Keywords: mobile phone; toxic metals; plastic component; printed wiring board; progression.

\section{Introduction}

Globally, mobile telephony has grown into a major industry in the last 30 years with an estimated 5 billion users around the world [1]. The consumers' attitude of always being attracted to the aesthetics and newer functionalities in more latest versions of electronic products could be influencing the original equipment manufacturers (OEMs) to always roll out products with shorter life spans so that their annual turnover will be greater. Within the last decade, the life span of a typical mobile phone has been put at 9 to 18 months depending on the OEM and how the phone is being used [2]. The ever-advancing telephony technology resulting in increase in product obsolescence and short life span have created an upsurge in the quantities of end-of-life (EoL) mobile phones being disposed of with concomitant toxic substances like $\mathrm{Pb}, \mathrm{Cd}, \mathrm{Cr}, \mathrm{Hg}$, flame retardants, etc. in the various components of the phones, which when improperly disposed of have deleterious consequences on both human health and the environment.

Many studies have reported approximate quantities of EoL mobile phones generated from different countries and regions of the globe [3-7]. In fact, it has been estimated that in the United States alone, over 300, 000 mobile phones are being disposed of daily [1]. A typical mobile phone weighing up to $100 \mathrm{~g}$ has been reported to contain over 40 different known metals in different components and in different concentrations [8]. Konstantinos et al. [9] explained in details the different components of a typical mobile phone and the average concentrations of major metals and other substances in these components.
As a result of high proportion of some toxic metal concentrations and other organic pollutants in various components of mobile phones and other electrical and electronic equipment (EEE), it is thought that adverse environmental impact could arise from improper management of these EEE at end of life [9, 10]. Within this context, many countries and regions of the world now have policies and regulations in force to restrict the amounts of selected toxic substances in EEE according to their conveniences and the dictates of the laws. Some of the regulations now in force in some countries and regions of the world include: "The European Union 2002/96/EC Waste Electrical and Electronic Equipment Directive" [11], "WEEE Recast Directive" [12], "European Union 2002/95/EC Restriction on Hazardous Substances (RoHS) Directive" [13], "Management methods for the restriction of the use of hazardous substances in electrical and electronic products" [14], "California Department of Toxic Substance Control Laws, Regulations and Policies" [15].

Most developing countries like Nigeria depend completely on imported new and used EEE products including mobile phones. It is perceived that many OEMs customize different EEE to fit each country's environmental laws instead of having a single bill of materials with potentials of being distributed worldwide. Against this backdrop, it is thought that many new EEE products arriving Nigerian shores are substandard possibly due to either weak or non-existence of regulations and enforcement. This could perhaps be the reason why Nigerians patronize a lot of imported fairly used EEE which have comparable prices with new ones and in many cases even more expensive. There is paucity

\footnotetext{
* Corresponding author. E-mail address: gildie1975@gmail.com, gu.adie@ mail.ui.edu.ng (Gilbert Umaye Adie)
} 
of data in literature on studies within the African region that comprehensively and systematically monitor the progression of toxic metal concentrations in mobile phone components produced for a reasonable period of time. Therefore, the objective of this study was to assess the progression of $\mathrm{Pb}, \mathrm{Cr}$ and $\mathrm{Cd}$ concentrations in $\mathrm{EoL}$ mobile phones produced between 2000 and 2015 found in repairers' workshops in Nigeria in order to evaluate the behavior of OEMs in regulating the content of the aforementioned metals in their products.

\section{Experimental}

\subsection{Sample collection}

A total of 59 EoL mobile phones produced by two leading original equipment manufacturers coded as OEM 1 and OEM 2 were obtained whole from repairers' shops in Nigeria. Thirty of the phones were produced by OEM 1 while twenty-nine others were produced by OEM 2 all between year 2000 and 2015. The model, date of manufacture (DoM) and country of manufacture (CoM) for each phone were identified and presented in Table 1.

Table 1. Details of mobile phones studied.

\begin{tabular}{|c|c|c|c|c|c|c|c|}
\hline \multicolumn{4}{|c|}{ Original Equipment Manufacturer 1} & \multicolumn{4}{|c|}{ Original Equipment Manufacturer 2} \\
\hline YoM & $\begin{array}{c}\text { Sample } \\
\text { No }\end{array}$ & IMEI number & CoM & YoM & $\begin{array}{c}\text { Sample } \\
\text { No }\end{array}$ & Serial number & CoM \\
\hline 2000 & 1 & $351342 / 80 / 151028 / 1$ & Finland & 2001 & 1 & R1XRC74116V & Korea \\
\hline 2000 & 2 & $350606 / 80 / 908103 / 7$ & Finland & 2003 & 2 & R4YX551718L & Korea \\
\hline 2001 & 3 & $352738 / 01 / 129370 / 1$ & Finland & 2003 & 3 & R5YX307236N & Korea \\
\hline 2002 & 4 & $858786 / 00 / 643903 / 5$ & Hungary & 2003 & 4 & R3VX967515D & Korea \\
\hline 2003 & 5 & $356672 / 00 / 428065 / 3$ & Hungary & 2004 & 5 & R7VX84672D3 & Korea \\
\hline 2003 & 6 & $352726 / 01 / 089122 / 8$ & Hungary & 2004 & 6 & RDYND29291D & Korea \\
\hline 2005 & 7 & $358376 / 00 / 542072 / 6$ & Hungary & 2005 & 7 & R4WA46504W & Korea \\
\hline 2005 & 8 & $358353 / 00 / 255050 / 8$ & China & 2005 & 8 & R2XTC71241A & Korea \\
\hline 2006 & 9 & $354841 / 02 / 488548 / 4$ & Finland & 2006 & 9 & RVUP408605L & China \\
\hline 2006 & 10 & $354759 / 00 / 168768 / 3$ & Hungary & 2006 & 10 & R6YAA66342B & Korea \\
\hline 2006 & 11 & $355516 / 01 / 251574 / 4$ & Hungary & 2006 & 11 & R2UA679986H & Korea \\
\hline 2007 & 12 & $356262 / 01 / 760739 / 7$ & Finland & 2007 & 12 & RPTQ828604L & China \\
\hline 2007 & 13 & $358250 / 03 / 112575 / 9$ & India & 2007 & 13 & R3UP628331K & Korea \\
\hline 2007 & 14 & $353261 / 01 / 953380 / 2$ & Finland & 2008 & 14 & RVMS223B2D & China \\
\hline 2008 & 15 & $358291 / 03 / 870576 / 7$ & India & 2008 & 15 & R6XY2442678 & Korea \\
\hline 2008 & 16 & A00000015B476E & China & 2008 & 16 & RVQQB13551R & Ireland \\
\hline 2008 & 17 & $356350 / 03 / 020984 / 4$ & Finland & 2009 & 17 & RVBZA33711M & China \\
\hline 2009 & 18 & $353398 / 04 / 127620 / 6$ & India & 2009 & 18 & R3WQA842RF & Korea \\
\hline 2009 & 19 & $352708 / 04 / 277956 / 8$ & India & 2010 & 19 & RPZZ13245AD & Philippines \\
\hline 2010 & 20 & $352426 / 05 / 005202 / 7$ & China & 2010 & 20 & RD6B482768H & India \\
\hline 2010 & 21 & $357420 / 04 / 488756 / 9$ & India & 2010 & 21 & RP5ZC82864B & China \\
\hline 2010 & 22 & $357921 / 04 / 405718 / 6$ & Romania & 2011 & 22 & RVHZ708688E & Korea \\
\hline 2011 & 23 & $359755 / 04 / 535037 / 4$ & India & 2011 & 23 & RF3BB96984L & China \\
\hline 2011 & 24 & $354474 / 05 / 148366 / 6$ & China & 2012 & 24 & R21C601Y1PF & China \\
\hline 2011 & 25 & $359764 / 04 / 209464 / 7$ & India & 2012 & 25 & R21D949P8SF & China \\
\hline 2012 & 26 & $354131 / 05 / 132344 / 7$ & India & 2012 & 26 & R21C62GFZ6R & China \\
\hline 2012 & 27 & $355758 / 34 / 278531 / 6$ & Finland & 2013 & 27 & R21D42SBB8B & China \\
\hline 2013 & 28 & $359568 / 03 / 762497 / 3$ & India & 2013 & 28 & RF1DA254DD & Vietnam \\
\hline 2013 & 29 & $358912 / 02 / 955634 / 1$ & China & 2014 & 29 & RF1D47RS3XT & Korea \\
\hline 2015 & 30 & $354759 / 00 / 168709 / 7$ & India & & & & \\
\hline
\end{tabular}

Total recoverable metals were extracted from each sample by adopting the US EPA 3050B Method designed to determine the amount of metals in a material that could become available under the worst-case environmental condition [16, 17]. Exactly $2 \mathrm{~g}$ of each sample were digested using $10 \mathrm{~mL}$ of $1: 1 \mathrm{HNO}_{3}$ for about 15 minutes and allowed to cool. $5 \mathrm{~mL}$ of concentrated $\mathrm{HNO}_{3}$ were added and the solution was heated for about 30 minutes and allowed again to cool. More aliquots of the concentrated $\mathrm{HNO}_{3}(5 \mathrm{~mL}$ at a time, 
amounting to $10 \mathrm{~mL}$ max per sample) were added and the heating process was repeated until no more brown fumes were evolved on heating. This indicated that there was completion of the digestion process. Thereafter, the sample solution was heated up to $90{ }^{\circ} \mathrm{C}$ without boiling for about an hour. The solution was then allowed to cool and $2 \mathrm{~mL}$ of deionized water and $3 \mathrm{~mL}$ of $30 \% \mathrm{H}_{2} \mathrm{O}_{2}$ were added and the heating process resumed, but gradually to avoid sample loss by effervescence until there was no obvious change in the appearance of the sample solution. Finally, $10 \mathrm{~mL}$ of concentrated $\mathrm{HCl}$ were added to the solution and again heated at about 95 ${ }^{\circ} \mathrm{C}$ for 15 minutes. The sample solution was allowed to cool; it was filtered through Whatman 41 filter paper into a $50 \mathrm{~mL}$ volumetric flask and made up to mark with deionized water. This process was repeated for each sample and the blank. All the extracts were stored in the refrigerator at about $4{ }^{\circ} \mathrm{C}$ until analysis.

Because the $\mathrm{pH}$ values of the selected samples for toxicity characteristic leaching procedure (TCLP) test were all $<5$, TCLP solution 1 and the samples were extracted by adopting the EPA 1311 method [18]. All extracts were analyzed for $\mathrm{Pb}, \mathrm{Cd}$ and $\mathrm{Cr}$ using Buck 205 flame atomic absorption spectrometer (England). The linear ranges for each metal were: $10 \mathrm{mg} / \mathrm{L}$ for $\mathrm{Pb}$ $(\lambda-217.0 \mathrm{~nm}), 2.00 \mathrm{mg} / \mathrm{L}(\lambda-228.9 \mathrm{~nm})$ and $5.00 \mathrm{mg} / \mathrm{L}$ for $\mathrm{Cr}(\lambda-357.9 \mathrm{~nm})$. The $r^{2}$ values indicating the linearity of the curve for the standards for all the metals ranged from $0.90-0.95$. Air-acetylene flame which has a less oxidizing nature was used. Analytical grade reagents were used throughout and all glassware used were soaked overnight in dilute $\mathrm{HNO}_{3}$ acid solution to remove any adsorbed metal on them.

\section{Results and discussion}

\subsection{Summary of metal concentrations in mobile phones components}

The summary of metal concentrations in both plastic components (PCs) and printed wiring boards (PWBs) for mobile phones (MPs) produced between 2000- 2015 by OEM 1 and OEM 2 is presented in Table 2. The average concentrations of $\mathrm{Pb}, \mathrm{Cr}$ and $\mathrm{Cd}$ in the $\mathrm{PCs}$ of all MPs followed the order $\mathrm{Cr}>>\mathrm{Pb}>>\mathrm{Cd}$ for OEM 1 and $\mathrm{Pb}>\mathrm{Cr}>>\mathrm{Cd}$ for OEM 2. It is obvious from the average results that OEM 1 utilized far more $\mathrm{Cr}$ in the PCs compared with OEM 2. It is well known that transition metals like $\mathrm{Cr}, \mathrm{Cd}, \mathrm{Cu}$, etc. are common inorganic pigments that are usually used to impact colors on materials [19]. The chemistry behind the color formation by transition metals is the $d-d$ transition arising from the transfer of an electron of a transition metal from a lower $d$-orbital to a higher energy $d$-orbital. Possibly this advantage was explored to impact colors on PCs of mobile phones studied. Therefore, the elevated concentration of $\mathrm{Cr}$ in the OEM 1 PCs may not be unconnected with this. The average metal concentrations in the PWBs of both OEM 1 and OEM 2 followed the trend $\mathrm{Pb}>\mathrm{Cr}>\mathrm{Cd}$. The major source of $\mathrm{Pb}$ in the PWBs has been identified to be from the $\mathrm{Sn} / \mathrm{Pb}$ solder which is used to join the wiring circuitry on the board [20]. The average $\mathrm{Pb}$ and $\mathrm{Cr}$ in PWBs in MPs produced by both OEM 1 and OEM 2 were higher than RoHS Directive limit of 1000 ppm, implying that this component must be handled with care as it is regarded as a hazardous material. Cadmium concentration in all components was far lower than the RoHS limit of 100 ppm. This could be a sign that the two OEMs studied have complied with $\mathrm{Cd}$ limit in their EEE components. It is worthy of note that total $\mathrm{Cr}$ was determined in the MP components in the present study, but RoHS Directive restrict only Cr (VI) species. Therefore, we may not draw a conclusion on $\mathrm{Cr}$ toxicity based on total $\mathrm{Cr}$ from RoHS perspective, the $\mathrm{Cr}$ content in the components provides a good insight on the amount of $\mathrm{Cr}$ still used in MP components. This was the same view by Konstantinos et al. [9]. The high standard deviations, in many cases far higher than mean indicated for all metals studied is a sign that the OEMs have different templates for designing perhaps different models, colors and above all for different countries, etc. It is recommended that OEMs should begin to unify their designs across board in an ecofriendly manner for environmental sustainability.

Table 2. Summary of metal concentrations $(\mathrm{mg} / \mathrm{kg})$ in mobile phone components.

\begin{tabular}{|c|c|c|c|c|c|c|c|c|c|c|c|c|}
\hline & \multicolumn{6}{|c|}{ Mobile phones produced between 2000 - 2015 by OEM 1} & \multicolumn{6}{|c|}{ Mobile phones produced between $2000-2015$ by OEM 2} \\
\hline & \multicolumn{3}{|c|}{ Plastic Components } & \multicolumn{3}{|c|}{ Printed Wiring Boards } & \multicolumn{3}{|c|}{ Plastic Components } & \multicolumn{3}{|c|}{ Printed Wiring Boards } \\
\hline & $\mathrm{Pb}$ & $\mathrm{Cr}$ & $\mathrm{Cd}$ & $\mathrm{Pb}$ & $\mathrm{Cr}$ & $\mathrm{Cd}$ & $\mathrm{Pb}$ & $\mathrm{Cr}$ & $\mathrm{Cd}$ & $\mathrm{Pb}$ & $\mathrm{Cr}$ & $\mathrm{Cd}$ \\
\hline Mean & 39.5 & 799 & 0.04 & 2626 & 794 & 0.07 & 219 & 149 & 0.57 & 2388 & 1209 & 0.48 \\
\hline $\begin{array}{l}\text { Standard } \\
\text { deviation }\end{array}$ & \pm 53.0 & \pm 1720 & \pm 0.19 & \pm 3056 & \pm 1368 & \pm 0.21 & \pm 399 & \pm 408 & \pm 1.07 & \pm 2740 & \pm 1326 & \pm 0.19 \\
\hline Median & 13.8 & 7.38 & LOD & 1000 & 119 & LOD & 20 & 1.50 & 0.25 & 1250 & 838 & 0.50 \\
\hline Range & $\begin{array}{l}5.00- \\
195\end{array}$ & $\begin{array}{l}\text { LOD- } \\
6050\end{array}$ & $\begin{array}{l}\text { LOD } \\
-1.00\end{array}$ & $\begin{array}{l}129- \\
9750\end{array}$ & $\begin{array}{l}\text { LOD- } \\
5488\end{array}$ & $\begin{array}{l}\text { LOD- } \\
1.00\end{array}$ & $\begin{array}{l}\text { LOD } \\
-1750\end{array}$ & $\begin{array}{l}\text { LOD } \\
-2170\end{array}$ & $\begin{array}{l}\text { LOD } \\
-5.75\end{array}$ & $\begin{array}{l}5.00- \\
12125\end{array}$ & $\begin{array}{l}\text { LOD- } \\
4000\end{array}$ & $\begin{array}{l}0.25- \\
1.00\end{array}$ \\
\hline $\begin{array}{l}\text { RoHS limit } \\
\text { TTLC limit }\end{array}$ & & & & $\begin{array}{l}\mathrm{Pb}-1 \\
\mathrm{~Pb}-1\end{array}$ & $\begin{array}{l}\mathrm{ppm} \\
\mathrm{ppm}\end{array}$ & & $\begin{array}{l}\mathrm{Cr}-1000 \mathrm{p} \\
\mathrm{Cr}-2500 \mathrm{p}\end{array}$ & & $\begin{array}{l}\mathrm{Cd}-1 \\
\mathrm{Cd}-\end{array}$ & & & \\
\hline
\end{tabular}

$n=30$ for mobile phones produced by OEM $1 ; n=29$ for mobile phones produced by OEM; LOD = Limit of detection $(\mathrm{mg} / \mathrm{L})-\mathrm{Pb}=0.04 ; \mathrm{Cd}=$ $0.01 ; \mathrm{Cr}=0.04$.

\subsection{Progression in the metal concentrations in phone components}

Figures $1-3$ present the progression in metal concentrations in MP components with year of manufacture. These presentations could assist in forecasting OEMs behavior in complying with Directives like EU and China RoHS Directives presently in force in European Union and China, respectively. The concentrations of $\mathrm{Pb}, \mathrm{Cr}$ and $\mathrm{Cd}$ in $\mathrm{PCs}$ of MPs produced in 2006 and 2007 by both OEM 1 and OEM 2 when EU and China RoHS Directives, respectively came into force $[13,14]$ were lower than limit of $1000 \mathrm{ppm}$ for $\mathrm{Pb}$ and $\mathrm{Cr}$ and $100 \mathrm{ppm}$ for $\mathrm{Cd}$, respectively, except for average $\mathrm{Cr}$ concentration in PCs produced by OEM 1 in 
2007 and 2012 which showed elevated concentrations higher than 1000 ppm limit (Fig. 1a\&b and 2a\&b). This trend is perceived to be due to the disparity in color, model and country of manufacture of the products. The concentrations of both $\mathrm{Pb}$ and $\mathrm{Cr}$ in PWBs of MPs produced between 2000 -2015 did not show any regular trends for both OEM 1 and OEM 2 (Figs 1a and 2a), but a critical look at $\mathrm{Pb}$ and $\mathrm{Cr}$ contents in MPs produced by OEM 1 (Fig. 1a) indicate a decrease in the metal levels in the later products especially in 2006 and 2007, the years when the EU RoHS and China RoHS, respectively came into force. The enforcement could have influenced the decrease. The same observation was made by Chen et al. [21]. Figure 3a indicates a comparison of average concentrations of $\mathrm{Pb}$ in MPs produced by OEM 1 and OEM 2. There seem to be no pronounced difference between $\mathrm{Pb}$ content in MPs produced by the two OEMs especially from 2006 when RoHS directive came into force. The $\mathrm{Pb}$ level fluctuated around the limit for both OEM 1 and 2 till 2011 when there was a steady rise far above the limit in the MPs components produced by both OEMs. This trend is not well understood, but it could be a sign that both OEMs could be producing different qualities of EEE depending on the country of manufacture and the dictates of the extant laws.

Figure $3 b$ presents a comparison of average $\mathrm{Cr}$ concentration in PCs and PWBs of the studied MPs. Chromium level also fluctuated in both components around the limit, but it was very obvious that the level in PCs produced by OEM 2 was lower than in OEM 1, suggesting as earlier indicated a higher patronage of the metal by OEM 1. Figure 3c indicates Cd concentration in the components. In a whole, Cd level was far below the limit of $100 \mathrm{ppm}$, but there seemed to be higher content in PCs arising from OEM 2 compared to OEM 1 , again suggesting difference in patronage by the two OEMs.

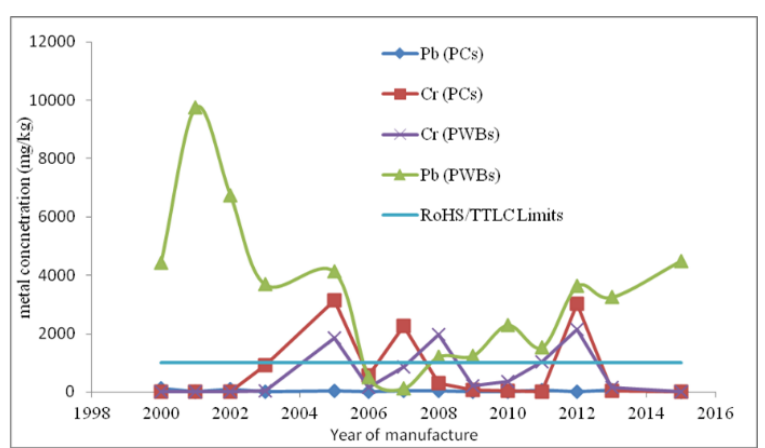

Figure 1a. Progression of $\mathrm{Pb}$ and $\mathrm{Cr}$ concentrations in mobile phones with year of manufacture for OEM 1.

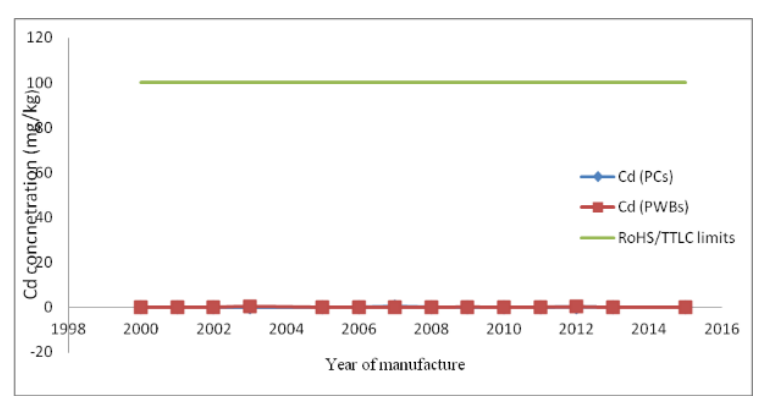

Figure 1b. Progression of $\mathrm{Cd}$ concentration in mobile phones with year of manufacture for OEM 1.

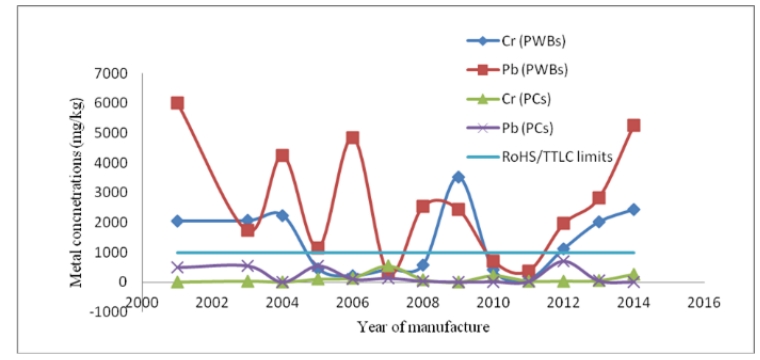

Figure 2a. Progression of $\mathrm{Pb}$ and $\mathrm{Cr}$ concentrations in mobile phones with year of manufacture for OEM 2.

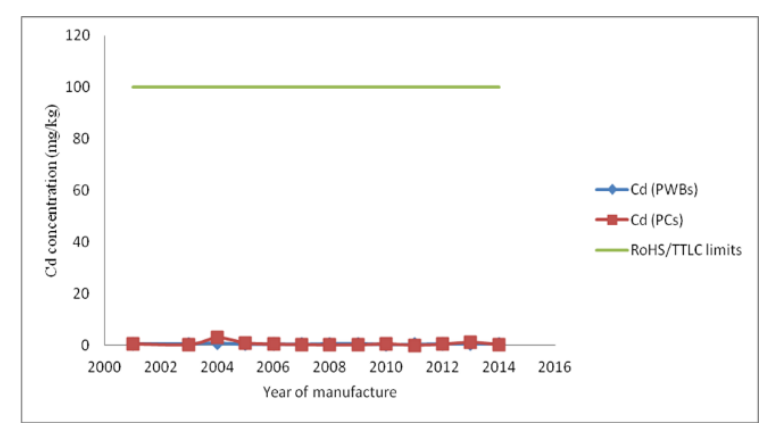

Figure 2b. Progression of Cd concentration in mobile phones with year of manufacture for OEM 2 .

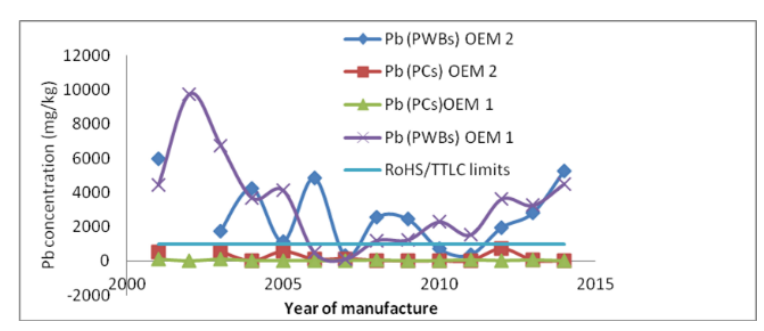

Figure 3a. Comparison of $\mathrm{Pb}$ concentration in mobile phones between OEM 1 and OEM 2.

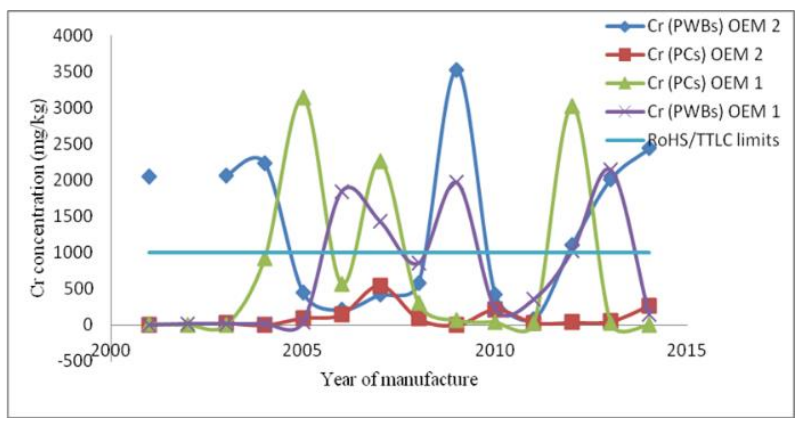

Figure 3b. Comparison of $\mathrm{Cr}$ concentration in mobile phones between OEM 1 and OEM 2

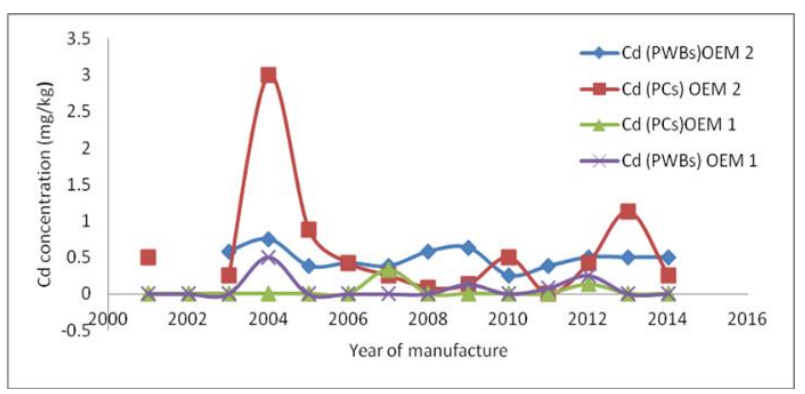

Figure 3c. Comparison of Cd concentration in mobile phones between OEM 1 and OEM 2 


\subsection{Distribution of mobile phones studied according to country of manufacture}

Figures $4 \mathrm{a}$ and $4 \mathrm{~b}$ show the distribution of MPs according to the country of manufacture. This distribution could provide some insight into linking the levels of the metals in components presented in Figs. 1 3 with OEMs' behavior in various countries. The 30 MPs produced by OEM 1 were found to be manufactured in 5 countries as shown in Table 1 and Fig. 4a. Finland, Hungary and Romania are EU countries; therefore, products from these countries should be regulated by EU RoHS Directive which came into force in 2006 and those from China by China RoHS Directive which came into force in 2007. Only India's RoHS is not yet in force. Also, the 29 MPs produced by OEM 2 were found to be from 6 countries, namely: China, India, Ireland, Korea, Philippines and Vietnam. Metals in products from Ireland should have been restricted by EU RoHS Directive and those from China by China RoHS as well. The other Asian countries do not seem to have specific EEE restriction policies or directives in force. An analysis of the results presented in Fig. 1a for instance, indicated that $\mathrm{Pb}$ and $\mathrm{Cr}$ contents in both PCs and PWBs produced in 2006 by OEM 1 were all lower than $1000 \mathrm{ppm}$ limit for the metals. These concentrations may have been influenced by EU RoHS Directive as the MPs for this year as presented in Fig. 4a were manufactured in Finland and Hungary and two out of the three MPs analyzed were of the same model (Table 1), thereby reducing disparity contributed by design. The drop-in metal content of products manufactured after 2006 compares with the study by Konstantinos et al. [9] who investigated the concentrations of selected metals in both PCs and PWBs of 24 obsolete MPs manufactured between 2002 and 2011 found in Greece, an EU country regulated by EU RoHS Directive. Interestingly, the authors found that on the one hand, $\mathrm{Pb}$ content in PWBs showed a sharp drop in MPs manufactured between 2007 - $2011(230-510$ $\mathrm{mg} / \mathrm{kg}$ ) compared with those manufactured between 2002 - $2006(100-27000 \mathrm{mg} / \mathrm{kg})$ and on the other hand $\mathrm{Cr}$ concentration in MPs manufactured between 2002 $2006(540-8500 \mathrm{mg} / \mathrm{kg})$ and $2007-2011(1500-4400$ $\mathrm{mg} / \mathrm{kg}$ ) showed lower concentrations in the more recent MPs, but $\mathrm{Cr}$ content was still above RoHS limit. This was a sign that the OEMs were shifting towards designing more eco-friendly products.

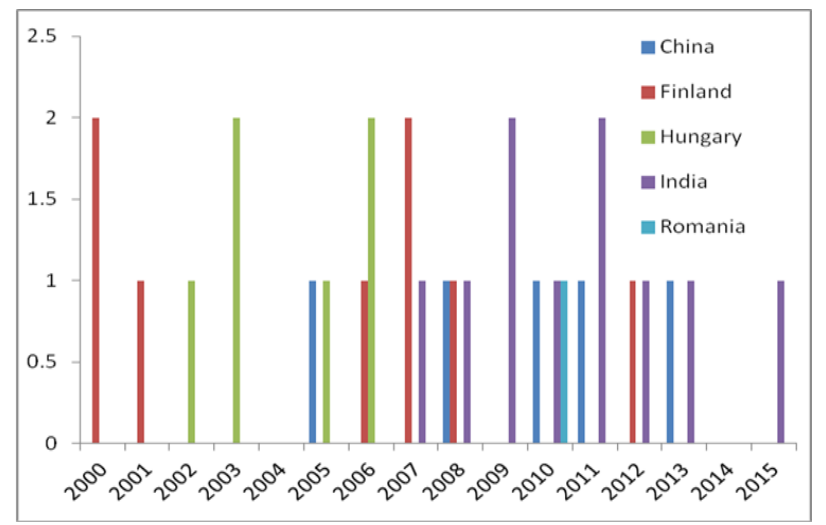

Figure 4a. Distribution of mobile phones produced by OEM 1 according to country of manufacture.

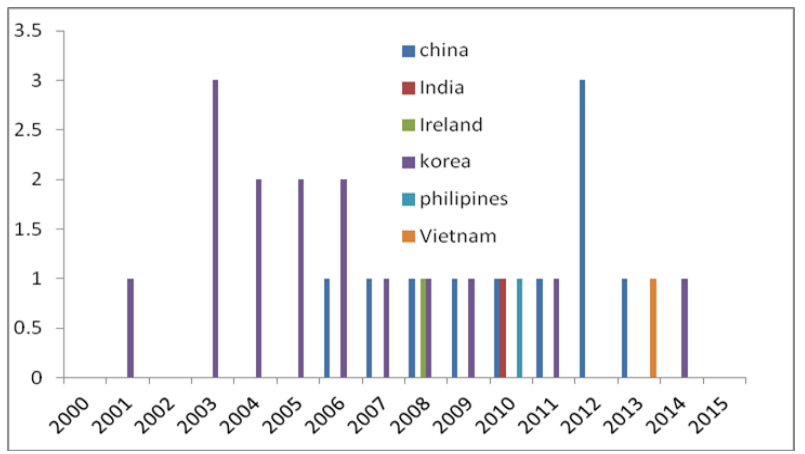

Figure 4b. Distribution of mobile phones produced by OEM 2 according country to of manufacture.

In the present study, the metal concentrations of especially $\mathrm{Pb}$ in $\mathrm{PWB}$ appeared to be on a steady rise in MPs produced from 2008. This seemed to be the trend for MPs manufactured by OEM 2 also. This trend could probably be influenced by MPs from countries like India for OEM 1 and Asian countries for OEM 2 where EEE specific restriction regulations are not yet in force. Furthermore, it could be a sign that the OEMs customize the concentrations of these restricted materials in different EEE to fit each country's environmental laws instead of having a single bill of materials with potential of being distributed worldwide. It is thought that some OEMs exploit this loophole to produce low quality products meant for export to especially developing countries (as already perceived in Nigeria) where there are either weak or no EEE specific policies/regulations. To buttress this perception, the EU and China RoHS Directives already in force, restrict certain potentially toxic materials in EEE products that are placed only in their countries $[13,14]$. One constraint noticed in this study was the inability to identify whether the EoL MPs studied were imported new or used since Nigerians patronize both new and used MPs imported into the country. The implication of these results points to the fact that the two OEMs whose products were studied have not completely complied with the generally accepted RoHS Directive as MPs from countries where RoHS Directive is already in force still contain $\mathrm{Pb}$ and $\mathrm{Cr}$ in some EoL MP components higher than required, thereby qualifying them as toxic materials. Some studies in literature revealed average $\mathrm{Pb}$ concentration in $\mathrm{PWBs}$ ranging from $12300-201000 \mathrm{mg} / \mathrm{kg}$ [22-25]. This range is higher than RoHS Directive limit by many folds, though the studies did not indicate the year and country of manufacture of the MPs investigated to correctly compare with RoHS Directive.

\subsection{Correlation and ANOVA tests}

Table 3 presents Pearson correlations and one-way analysis of variance (ANOVA) both at $95 \%$ significant level between $\mathrm{Pb}, \mathrm{Cr}$ and $\mathrm{Cd}$ to study the association of their sources of origin and to compare the averages (means) of the metals, respectively in MPs manufactured by OEM 1 and 2 to know if there is any significant difference between the metal concentrations in them. On the one hand, the $p$ values for all pairs except $\mathrm{Pb} / \mathrm{Cr}(p=0.0001)$ for OEM 2 (Table 2) were $p$ $>0.05$, implying no significant differences between the pairs thereby indicating that was close association of 
their sources. On the other hand, the $F$ values arising from the comparison of average metal concentrations in components of mobile phones manufactured by OEM 1 and OEM 2 indicate that there were no significant differences in the concentrations of $\mathrm{Pb}$ and $\mathrm{Cr}$ in MP components manufactured by OEM 1 and OEM 2 as the $F$ values for the metals were $>0.05$, but there was for Cd (Table 2).

Table 3. Correlation and ANOVA tests.

\begin{tabular}{|c|c|c|c|c|}
\hline & & $\mathbf{P b}$ & $\mathrm{Cr}$ & Cd \\
\hline \multirow{7}{*}{$\begin{array}{l}\text { Pearson } \\
\text { corre- } \\
\text { lation }\end{array}$} & & & ${ }^{\alpha}-0.258(p=0.184)$ & $0.079(p=0.670)$ \\
\hline & $\mathrm{Pb}$ & 1 & ${ }^{\beta}[0.688(p=$ & {$[0.029(p=$} \\
\hline & & & $0.0001)]$ & $0.889)]$ \\
\hline & & & \multirow{4}{*}{1} & $0.203(p=0.30)$ \\
\hline & $\mathrm{Cr}$ & & & {$[-0.005(p=$} \\
\hline & & & & 0.981)] \\
\hline & $\mathrm{Cd}$ & & & 1 \\
\hline One-way & & \multirow{3}{*}{0.644} & \multirow{3}{*}{0.992} & \multirow{3}{*}{0.000028} \\
\hline ANOVA & & & & \\
\hline$F$ values & & & & \\
\hline
\end{tabular}

\subsection{Leaching studies}

Table 4 presents the summary of TCLP test on PWBs of mobile phones manufactured by OEM 1 and OEM 2. The results for PCs were omitted because all metals in the PCs for all phones were below detection limits of $0.05 \mathrm{mg} / \mathrm{L}, 0.02 \mathrm{mg} / \mathrm{L}$ and $0.002 \mathrm{mg} / \mathrm{L}$ for $\mathrm{Pb}, \mathrm{Cr}$ and $\mathrm{Cd}$, respectively. 50\% PWBs arising from MPs made by both OEM 1 and OEM 2 were higher than EPA limit of $5 \mathrm{mg} / \mathrm{L}$. The TCLP results were within the same ranges with a study by Lincoln et al. [22] who examined mobile phone components with ranges $(\mathrm{mg} / \mathrm{L})$ of $34.2-147$ for $\mathrm{Pb}, 0.04-0.13$ for $\mathrm{Cr}$ and $0.0006-0.006$ for $\mathrm{Cd}$, respectively. It is thought that $\mathrm{Cr}$ and $\mathrm{Cd}$ were detected in this study because Inductively Plasma - Mass Spectrometer, a more sensitive with lower detection limits for the metals was used.

Table 4. Summary of leaching studies on mobile phone components.

\begin{tabular}{|c|c|c|c|c|}
\hline \multicolumn{2}{|c|}{ OEM 1 (PWBs) } & $\begin{array}{l}\text { OEM } 2 \\
\text { (PWBs) }\end{array}$ & $\begin{array}{c}\text { TCLP limit } \\
\mathrm{mg} / \mathrm{L}\end{array}$ & \\
\hline $\begin{array}{c}\text { Total } \\
\text { recoverable } \\
(\mathrm{mg} / \mathrm{kg})\end{array}$ & $\begin{array}{c}\text { TCLP } \\
(\mathrm{mg} / \mathrm{L})\end{array}$ & $\begin{array}{c}\text { Total } \\
\text { recoverable } \\
(\mathrm{mg} / \mathrm{kg})\end{array}$ & $\begin{array}{c}\text { TCLP } \\
(\mathrm{mg} / \mathrm{L})\end{array}$ & \\
\hline $\mathrm{Pb}$ & $\mathrm{Pb}$ & $\mathrm{Pb}$ & $\mathrm{Pb}$ & \\
\hline 9750 & 92.8 & 6000 & 109 & 5 \\
\hline 7750 & 38.8 & 925 & 144 & 5 \\
\hline 250 & 0.11 & 3000 & 0.29 & 5 \\
\hline 2125 & 39.4 & 3925 & 288 & 5 \\
\hline 3375 & 0.51 & 4875 & 10.8 & 5 \\
\hline 250 & 0.42 & 125 & 0.57 & 5 \\
\hline 7000 & 35.9 & 1500 & 0.27 & 5 \\
\hline 5500 & 50.7 & 4375 & 10.3 & 5 \\
\hline
\end{tabular}

Detection limit: $\mathrm{Pb}-0.05 \mathrm{mg} / \mathrm{L}$

\section{Conclusion}

This study presents an evaluation of $\mathrm{Pb}, \mathrm{Cr}$ and $\mathrm{Cd}$ contents in plastic components and printed wiring boards of 59 mobile phones made between year 2000 2015 in 11 different countries across Asia and Europe by two leading original equipment manufacturers. The results revealed that despite the restrictions of the aforementioned metals by one of the most widely and globally accepted directive, the RoHS Directive, $\mathrm{Pb}$ and $\mathrm{Cr}$ were still found especially in printed wiring boards higher than RoHS limits even in mobile phones manufactured in countries where RoHS Directive was already in force. This is a wake-up call to encourage the OEMs to adopt the principle of manufacture-forenvironment by shifting towards designing more ecofriendly products to safeguard human health and the entire environment. Furthermore, EOMs should implement the policy of a single bill of materials with the intention of being distributed worldwide, instead of perhaps customizing less quality materials based on the extant regulations for countries with weaker or no enforcement of restriction laws in place.

\section{Conflict of interest}

No conflict of interest declared.

\section{References}

[1]. Underwriters Laboratories Inc (UL), the life cycle of materials in mobile phones, UL White paper. http://library.ul.com/wp-

content/uploads/sites/40/2015/02/ULE_CellPhone White_Paper_V2.pdf. 2011. (accessed 24.08.2017).

[2]. O. Osibanjo, I.C. Nnorom, Material flows of mobile phone and accessories in Nigeria: environmental implications and sound end-of-life management options, Environ. Impact Asses. 28 (2008) 198-213.

[3]. L. Canning, Rethinking market connections: mobile phone recovery, reuse and recycling in the UK, J. Bus. Ind. Mark. 21 (2006) 320-329.

[4]. Z. Yongguang, Y. Qingdong, W. Peng, W. Guohong,W, A research into the recycling system of waste electrical and electronic equipment in China, in: 2006 IEEE International Conference on Service Operations and Logistics and Informatics, 2006.

[5]. M. Polak, L. Drapalova, Estimation of end of life mobile phones generation: the case study of Czech Republic, Waste Manage. 32 (2012)1583-1591.

[6]. B. K. Fishbein, Waste in the wireless world, the challenge of cell Phones, INFORM, Inc., New York, 2002.

[7]. O. Odeyingbo, I. Nnorom, O. Deubzer, R. Kühr, O. Osibanjo, P. Onianwa, G. Adie, S. Adrian, K. Willke, The person-in-the-Port Project: volumes and quality of used electronics imports into Nigeria, paper presented at the Electronic goes green (EGG) conference, Berlin, Germany, 2016. DOI: 10.1109/EGG.2016.7829838

[8]. M. Schluep, C. Hagelueken, R. Kuehr, F. Magalini, C. Mauer, C. Meskers, E. Mueller, F. Wang, Recycling from e-waste to resources, Final Report, United Nations Environment Program, United Nations University, http:www.unep.org/PDF/./Ewaste_publication_screen_FINALVERSIONsmi. Pdf. 2009 (assessed 15.09.2017).

[9]. G. Konstantinos, J. N. Maragkos, E. G. Hahladakis, Qualitative and quantitative 
determination of heavy metals in waste cellular phones, Waste Management 33 (2013) 1882-1889.

[10]. R. Geyer, V. Doctori-Blass, The economics of cell phone reuse and recycling. Int. J. Adv. Manuf. Technol. 47 (2010) 515-525.

[11]. EU WEEE Directive, Commission of the European Communities Directive 2002/96/EC of the European Parliament and of the Council on waste electrical and electronic equipment (WEEE). Off. J. Eur. Union L37 (2003) 24-38.

[12]. EU WEEE Recast Directive 2012/19/EU of the European Parliament and of the council of on waste electrical and electronic equipment (WEEE). Off. J. Eur. Union, 2003. http://dx.doi.org/10.3000/19770677.L_2012.197.e ng (accessed 15.09.2017)

[13]. RoHS Directive 2002/95/EC of the European Parliament and of the Council of on the restriction of the use of certain hazardous substances in electrical and electronic equipment. Off. J. Eur. Union L37 (2003) 19-23.

[14]. China RoHS 2, Management methods for the restriction of the use of hazardous substances in electrical and electronic products, Ministry of Industry and Information Technology Regulation, https://www.manufacturingindustryadvisor.com/c hinas-rohs-2-regulation-what-manufacturersmust-know/.2016 (accessed 24.08.2017).

[15]. Department of Toxic Substances Control (DTSC), Control laws, regulations and policies, California Department of Toxic Substance, http://www.dtsc.ca.gov/LawsRegsPolicies/Regs/i ndex.cfm.2010 (accessed 24.08.2017).

[16]. Environmental Protection Agency, Acid digestion of sediments, sludge and soils, EPA 3050B Method, United States Environmental Protection Agency, Revision 2. https://www.epa.gov/sites/production/files/201506/documents/epa-3050b.pdf, December, 1996 (accessed 28.08.2017).

[17]. T. G. Townsend, Environmental issues and management strategies for waste electronic and electrical equipment, J. Air Waste Manage. Assoc. 61 (2011) 587-587.

[18]. EPA Method 1311, Toxicity characteristic leaching procedure, Specifications of the Committee on Analytical Reagents of the American Chemical, U.S. Environmental Protection Agency, USA, 1992.

[19]. The Editors of Encyclopædia Britannica, Plastic composition, https://www.britannica.com/science/plastic.2017 (accessed 07.09.2017).

[20]. G.U. Adie, L. Sun, X. Zeng, L. Zheng, O. Osibanjo, J. Li, Examining the evolution of metals utilized in printed circuit boards, Environ. Technol. 38 (2017) 1696-1701.

[21]. M. Chen, O.A. Ogunseitan, J. Wang, H. Chen, B. Wang, S. Chen, Evolution of electronic waste toxicity: Trends in innovation and regulation, ENVINT 89-90 (2016) 147-154.

[22]. D.L. Lincoln, O.A. Ogunseitan, A.A. Shapiro, J.D.M. Saphores, Leaching assessments of hazardous materials in cellular telephones, Environ. Sci. Technol. 41 (2007) 2572-2578.

[23]. H.L. Yamane, V.T. Moraes, D.C.R. Espinosa, J.A.S. Tenorio, Recycling of WEEE: characterization of spent printed circuit boards from mobile phones and Computers, Waste Manage. 31 (2011) 2553-2558.

[24]. A.C. Kasper, G.B.T. Berselli, B.D. Freitas, J.S.A. Tenorio, A.M. Bernardes, H.M. Veit, Printed wiring boards for mobile phones: characterization and recycling of copper, Waste Manage. 31 (2011) 2536-2545.

[25]. I.C. Nnorom, O. Osibanjo, Determination of metals in printed wiring boards of waste mobile phones, Toxicol. Environ. Chem. 93 (2011) 15571571.

Received: 16.03.2019

Received in revised form: 19.04.2019

Accepted: 24.04.2019 